\title{
ANTITUMOR POTENTIAL OF HYDROETHANOLIC EXTRACT OF ANNONA MURICATA LEAVES AGAINST DALTON'S LYMPHOMA ASCITES-INDUCED TUMOR IN MICE
}

\author{
NALINI P, BRINDHA DURAIRAJ* \\ Department of Biochemistry, PSG College of Arts and Science, Coimbatore, Tamil Nadu, India. Email: brindhavenkatesh6@gmail.com
} Received: 28 September 2017, Revised and Accepted: 14 December 2017

ABSTRACT

Objective: The objective of this study was to assess the antitumor activity of hydroethanolic extract of Annona muricata (HEEAM) in Dalton's lymphoma ascites (DLA)-induced tumor model.

Methods: Antitumor activity of HEEAM was evaluated against DLA-induced tumor mice by assessing the antitumor, hematological, and biochemical parameters.

Results: The results revealed that antitumor activity of HEEAM was observed in Swiss albino mice at the doses of $200 \mathrm{and} 400 \mathrm{mg} / \mathrm{kg}$ body weight given orally for 15 days. The results indicated that administration of the extracts not only increased the survival of animals and decreased the body weight with ascites tumor but also altered many hematological and biochemical parameters. Both extracts exhibited a significant $(p<0.05)$ antitumor activity on dose-dependent manner. Among the two doses, $400 \mathrm{mg} / \mathrm{kg}$ of HEEAM dose showed potent anticancer activity.

Conclusion: The findings confirmed that the HEEAM possess potent antitumor activity, and hence, it might be used as a natural anticancer agent.

Keywords: Annona muricata, Dalton's lymphoma ascites, Antitumor activity.

(C) 2018 The Authors. Published by Innovare Academic Sciences Pvt Ltd. This is an open access article under the CC BY license (http://creativecommons. org/licenses/by/4. 0/) DOI: http://dx.doi.org/10.22159/ajpcr.2018.v11i3.22807

\section{INTRODUCTION}

Nature is considered to be the most valuable source of therapeutic compounds due to its enormous chemical diversity in plant species. Plants contain naturally occurring phytochemicals as a rich source of antioxidants and possessing free radical scavenging property. Most of the secondary metabolites and their derivatives such as flavonoids and phenols from the different parts of the plant are being widely used to combat cancer by various mechanisms [1].

Cancer is an abnormal type of tissue growth in which the cells exhibit an uncontrolled division in an autonomous fashion. It leads to a progressive increase in the number of dividing cells which is a major health issue worldwide [2]. Lymphoma is a disease of the lymphocytes and the lymphatic system. Dalton's lymphoma ascites (DLA) is a transplantable, poorly differentiated malignant tumor which appeared originally as lymphocytes in the mouse. It grows in both solid and ascitic forms [3]. The ethnomedicinal dietary antimutagens and anticarcinogens from plants are widely used to treat various types of cancer effectively [4].

Annona muricata L. commonly known as graviola or soursop belongs to the family of Annonaceae. Conventionally, all parts of A. muricata are used by different ethnic communities for the treatment of tumor due to the various phytoconstituents present in it. The present study was designed to investigate the antitumor activity of the hydroethanolic extract of A. muricata (HEEAM) leaves against Dalton's lymphoma ascites-induced tumor models.

\section{METHODS}

Plant material and extraction

A. muricata leaves were collected in Coimbatore and were authenticated by Botanical Survey of India, TNAU, and Coimbatore. The authentication number for the plant was BSI/SRC/5/23/2015/Tech/153. The leaves of $A$. muricata were shade dried, powdered, and extracted (190g) with hydroethanol in a Soxhlet extractor for 18-20 h. The extract was concentrated to dryness in a rotary evaporator under reduced pressure and controlled temperature $\left(40-50^{\circ} \mathrm{C}\right)$. The extract was preserved in a refrigerator at $4^{\circ} \mathrm{C}$ for further use.

\section{Experimental animals}

Healthy Swiss Albino male mice weighing 25-30 g were obtained from the Amala Cancer Research Centre, Thrissur, Kerala, India. The mice were grouped and housed in polyacrylic cages and maintained under standard conditions $\left(25^{\circ} \mathrm{C}\right)$ with a $12 \mathrm{~h}$ dark/light cycle. The animals were fed with rat pellet feed and water ad libitum. All procedures described were reviewed and approved by the Animal Ethical Committee and study was conducted after obtaining Ethical Committee Clearance Number (KMCRET/Ph.D/08/2017-18).

\section{Induction of lymphoma}

DLA cells were obtained from Amala Cancer Research Centre, Thrissur, Kerala, India. The cells were maintained in vivo in Swiss albino mice by intraperitoneal transplantation of $1 \times 10^{6}$ cells/mouse. The DLA cells aspirated from the peritoneal cavity of mice were washed with saline and given intraperitoneally to develop ascitic tumor to all experimental animals except the normal group.

\section{Experimental design}

Swiss Albino mice were divided into six groups $(n=6)$. All the animals were injected with DLA cells $\left(1 \times 10^{6}\right.$ cells/mouse $)$ intraperitoneally except for the normal group. This was considered as day 0. Group I served as normal and Group II served as the tumor control. Group III and IV were treated with HEEAM at 200 and $400 \mathrm{mg} / \mathrm{kg}$ body weight, respectively. Group V served as a positive control and was treated with a suspension of methotrexate at $3.4 \mathrm{mg} / \mathrm{kg}$ body weight. All these treatments were given $24 \mathrm{~h}$ after the tumor inoculation, Group III and IV were injected HEEAM (200 and $400 \mathrm{mg} / \mathrm{kg} \mathrm{bw}$ ) once daily for 15 days. After the last dose and $24 \mathrm{~h}$ fasting, six mice from each group were sacrificed for the study of antitumor, hematological, and biochemical parameters. The blood was collected from the animals 
by retro-orbital puncture under slight anesthesia (diethyl ether), and the hematological parameters were estimated using a cell analyzer. The serum was separated from the rest of the blood by keeping it at $37^{\circ} \mathrm{C}$ for half an hour and subjected for the estimation of biochemical parameters.

Rest of the animals in each group were kept alive with food and water ad libitum to check the percentage increase in life span of the tumor host and also to determine the mean survival time (MST). Antitumor activity of HEEAM was assessed by the observation of changes with respect to the following parameters [5].

\section{Tumor volume and weight}

The mice were dissected and the ascitic fluid was collected from the peritoneal cavity. Volume of the fluid was measured by taking it in graduated centrifuge tube. Tumor weight was measured by taking the weight of the mice before and after the collection of the ascitic fluid from peritoneal cavity.

\section{Percentage increase life span (ILS)}

The effect of HEEAM on tumor growth was monitored by recording the mortality of the experimental mice. The percentage ILS was calculated by the following formula: MST in days $=$ (day of first death + day of last death $) / 2$ ILS $(\%)=[$ (MST of the treated group/MST of the control group)-1] $\times 100$.

\section{Hematological parameters}

The collected blood was used for the estimation of hemoglobin $(\mathrm{Hb})$, red blood cell (RBC), white blood cell (WBC), mean corpuscular $\mathrm{Hb}$ concentration (MCHC), mean corpuscular volume (MCV), mean corpuscular $\mathrm{Hb}(\mathrm{MCH})$, packed cell volume (PCV), platelet, RBC distribution width (RDW), and differential count by standard procedures [6].

\section{Serum biochemical parameters}

Estimation of the liver marker enzymes such as aspartate transaminase (SGOT), alanine transaminase (SGPT), alkaline phosphatase, urea, and creatinine was carried out in the serum samples using Standard Kit method (Genei diagnostics).

\section{Statistical analysis}

The results obtained were reported as mean \pm standard deviation. The significance of the data was analyzed by one-way ANOVA followed by Tukey-Kramer multiple comparison tests and $\mathrm{p}<0.05$ was considered as statistically significant.

\section{RESULTS AND DISCUSSIONS}

\section{Antitumor parameters}

Body weight is an indirect parameter for health index of animals, and hence, it is easier to recover from the disease [7]. Effect of HEEAM on antitumor parameters in DLA-bearing mice is represented in Fig. 1. The body weight of the DLA-induced mice was found to be significantly increased when compared to normal group. Administration of HEEAM significantly decreased the body weight when compared with those of DLA-induced mice.

The MST was noticed as 24.38 days for control group, whereas it has been increased to $27.76,31.10$, and 36.13 days on administration of two different concentration of leaves extract (200 and $400 \mathrm{mg} / \mathrm{kg} \mathrm{bw}$ )
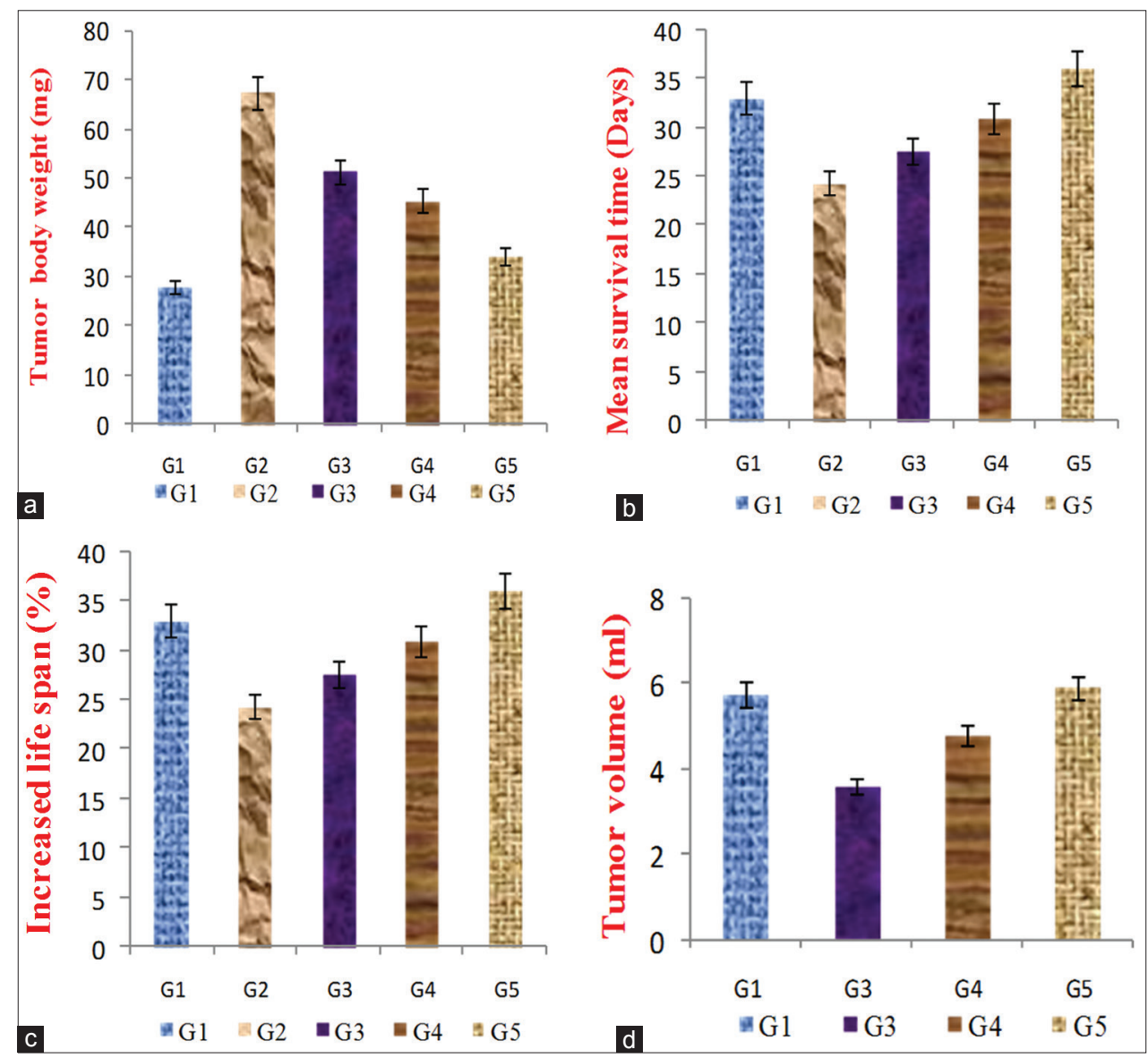

Fig. 1: Effect of hydroethanolic extract of Annona muricata (HEEAM) on Dalton's lymphoma ascites (DLA) tumor-bearing mice. G1 - Normal control, G2 - DLA control, G3 - HEEAM $200 \mathrm{mg} / \mathrm{kg}$, G4 - HEEAM $400 \mathrm{mg} / \mathrm{kg}$, G5 - Methotrexate $3.4 \mathrm{mg} / \mathrm{kg}$. (a) Tumor body weight. (b) MST - mean survival time (C) \% Increase in life span (ILS). (D) Tumor volume. Data are expressed as the mean \pm standard deviation of six animals. Values are significant at $\mathbf{p}<\mathbf{0 . 0 5}$ when compared with DLA control group. 
and standard drug (methotrexate at $3.4 \mathrm{mg} / \mathrm{kg}$ bw concentration), respectively. The percentage increases in the lifespan (\% of ILS) of tumorbearing mice treated with leaves extracts (200 and $400 \mathrm{mg} / \mathrm{kg} \mathrm{bw}$ ) and methotrexate was found to be $26.0,33.5$, and 34.16 , respectively. However, tumor volume was found to be significantly increased in DLA-induced mice. Coadministration of two different leaves extracts reverted back to near normal. The above results clearly indicated that both doses of $A$. muricata leaves extract have a remarkable capacity to inhibit the growth of tumor and it increased the life span by decreasing the PCV and thus arrested the tumor growth. Our results are in good accordance with work done by Sundaresan and Subbiah 2012 [8] reported that the treatment with methanolic extract of Chondrococcus hornemanni and Spyridia fusiformis inhibited the tumor volume and increased the life span of the tumor-bearing mice. Apart from the above, Jeena et al. 2015 [9] revealed that the treatment with ginger essential oil reduced the tumor volume, viable tumor cell count, and increased the life span of tumor-bearing mice.

\section{Hematological parameters}

Hematological parameters play an important role in assessing the degree of malignancy and restoration of health [10]. Effect of HEEAM on hematological parameters in DLA-bearing mice is represented in Table 1. In DLA-induced mice, a significant increase in total WBC count, platelets, MCHC, MCH, PCV, RDW, lymphocytes, neutrophils, and eosinophills was observed. Whereas, significant reduction in the $\mathrm{Hb}$ content, MCV, RBC, and lymphocytes was observed in tumor-bearing mice when compared with normal ones. However, coadministration of two different concentrations of A. muricata leaves extract (200 and $400 \mathrm{mg} / \mathrm{kg} \mathrm{bw}$ ) significantly decreased total WBC count, platelets, MCHC, MCH, RDW, lymphocytes, neutrophils, and eosinophills, and significantly increased the $\mathrm{Hb}$ content, MCV, RBC, and lymphocytes to maximum extent.

Based on the above observation, it is evident that both doses of A. muricata leaves extract have a remarkable capacity to revert the hematological parameters. This indicates a protective effect of A. muricata leaves extract on the hemopoietic system. Our results are in par with the work done by Santhoshkumar et al., 2008 [11] who stated that the plant extract of Hypericum hookerianum altered the hematological parameters during the tumor progression and indicated the potent antitumor nature of the extract.

\section{Biochemical parameters}

Biochemical markers are indicators for diagnosis and prognosis of malignant diseases [12]. The results of liver marker enzymes in DLA-bearing mice are depicted in Table 2. In DLA-induced mice, the activity of liver marker enzymes such as SGOT and SGPT, and the biochemical parameters such as urea, uric acid, and creatinine content were significantly increased when compared to normal. All the above parameters were reverted back to near normal levels on administration of two different doses of leaves extract ( 200 and $400 \mathrm{mg} / \mathrm{kg} \mathrm{bw}$ ). Our results suggested that the increased activity of marker enzymes in tumor animals was brought back to near normal which might be due to the therapeutic efficacy of the HEEAM. This study is in accordance with Sakthivel and Guruvayoorappan 2013 [13] reported that the methanolic extract of Acacia nilotica reverted the increased levels of marker enzymes to normal. Further, DeWys, 1982 [14] also reported that the presence of tumor in humans or experimental animals is recognized to affect the several functions of the vital organs, especially in the liver, even when the site of the tumor does not interfere directly with organ functions.

\section{CONCLUSION}

Our findings confirmed that both the concentration of leaves extract ( 200 and $400 \mathrm{mg} / \mathrm{kg} \mathrm{bw}$ ) exerts protection against the experimental animals from the deleterious effect of DLA-induced tumor in mice. Hence, it is proved that it possesses potent antitumor activity. However, in comparison with two different concentrations of the leaves extract, $400 \mathrm{mg} / \mathrm{kg}$ bw offered better curative effect than that of $200 \mathrm{mg} / \mathrm{kg}$ bw. This proved a strong evidence for the use of the A. muricata leaves in folklore treatment as anticancer agent. To support the above, further, investigation is required in animal model to elucidate the exact mechanism of action and to isolate its active constituents.

Table 1: Effect of HEEAM on hematological parameters in DLA-bearing mice

\begin{tabular}{|c|c|c|c|c|c|}
\hline Parameters & Normal control & DLA control $\left(1 \times 10^{6}\right.$ cells $)$ & $\begin{array}{l}\text { DLA+HEEAM } \\
(200 \mathrm{mg} / \mathrm{kg})\end{array}$ & $\begin{array}{l}\text { DLA+HEEAM } \\
(400 \mathrm{mg} / \mathrm{kg})\end{array}$ & $\begin{array}{l}\text { DLA+Methotrexate } \\
\text { (3.4 mg/kg) }\end{array}$ \\
\hline $\mathrm{Hb}(\mathrm{g} / \mathrm{dl})$ & $12.45 \pm 0.37$ & $8.23 \pm 0.21$ & $10.6 \pm 0.38$ & $11.85 \pm 0.54$ & $11.93 \pm 0.73$ \\
\hline $\mathrm{RBC}\left(10^{6} / \mathrm{mm}^{3}\right)$ & $6.85 \pm 0.15$ & $2.74 \pm 0.22$ & $4.76 \pm 0.10$ & $3.67 \pm 0.10$ & $5.74 \pm 0.36$ \\
\hline WBC $\left(10^{3} / \mathrm{mm}^{3}\right)$ & $5.95 \pm 0.28$ & $14.55 \pm 0.41$ & $6.61 \pm 0.33$ & $8.47 \pm 0.22$ & $7.25 \pm 0.20$ \\
\hline Platelet $\left(10^{3} / \mu \mathrm{l}\right)$ & $516.6 \pm 12.03$ & $838.4 \pm 26.34$ & $778.4 \pm 15.97$ & $722.6 \pm 16.54$ & $645.4 \pm 18.70$ \\
\hline $\mathrm{MCHC}(\mathrm{mg} / \mathrm{dl})$ & $31.68 \pm 0.22$ & $35.58 \pm 0.28$ & $31.61 \pm 0.27$ & $32.64 \pm 0.23$ & $32.52 \pm 0.31$ \\
\hline $\operatorname{MCV}(\mathrm{fl})$ & $75.93 \pm 2.43$ & $63.39 \pm 2.10$ & $65.82 \pm 2.03$ & $68.94 \pm 1.98$ & $72.09 \pm 2.85$ \\
\hline PCV (\%) & $25.32 \pm 1.32$ & $39.45 \pm 2.03$ & $35.63 \pm 1.84$ & $30.72 \pm 1.54$ & $27.35 \pm 1.27$ \\
\hline RDW (\%) & $15.39 \pm 0.28$ & $20.49 \pm 0.40$ & $18.53 \pm 0.30$ & $17.42 \pm 0.28$ & $17.45 \pm 0.38$ \\
\hline Lymphocytes (\%) & $64.05 \pm 3.39$ & $40.52 \pm 3.48$ & $47.39 \pm 2.10$ & $57.77 \pm 1.54$ & $60.51 \pm 2.53$ \\
\hline Neutrophils (\%) & $29.01 \pm 1.81$ & $67.10 \pm 1.24$ & $46.54 \pm 1.31$ & $40.38 \pm 1.49$ & $35.62 \pm 1.54$ \\
\hline Eosinophils (\%) & $4.50 \pm 0.54$ & $5.15 \pm 0.75$ & $4.68 \pm 0.53$ & $5.50 \pm 0.37$ & $6.20 \pm 0.33$ \\
\hline
\end{tabular}

Data are expressed as the mean \pm SD of six animals. Values are significant at $p<0.05$. When compared with DLA control group. Hb: Hemoglobin, RBC: Red blood cell, WBC: White blood cell, MCHC: Mean corpuscular hemoglobin concentration, MCV: Mean corpuscular volume, MCH: Mean corpuscular hemoglobin, PCV: Packed cell volume, RDW: Red blood cell distribution width, DLA: Dalton's lymphoma ascites, HEEAM: Hydroethanolic extract of Annona muricata

Table 2: Effect of HEEAM on biochemical parameters in DLA-bearing mice

\begin{tabular}{|c|c|c|c|c|c|}
\hline Parameters & SGOT (U/L) & SGPT (U/L) & Urea (mg/dl) & Uric acid (mg/dl) & Creatinine (mg/dl) \\
\hline Normal control & $78.40 \pm 0.04$ & $58.08 \pm 0.68$ & $32.48 \pm 0.54$ & $4.46 \pm 0.38$ & $1.39 \pm 0.32$ \\
\hline DLA control $\left(1 \times 10^{6}\right.$ cells/mouse $)$ & $95.49 \pm 0.21$ & $71.58 \pm 0.26$ & $45.12 \pm 2.42$ & $7.33 \pm 0.48$ & $1.59 \pm 0.57$ \\
\hline DLA+HEEAM 200 mg/kg & $78.61 \pm 0.20$ & $63.52 \pm 0.23$ & $39.13 \pm 0.56$ & $5.30 \pm 0.34$ & $0.52 \pm 0.27$ \\
\hline DLA+HEEAM 400 mg/kg & $75.57 \pm 0.18$ & $60.49 \pm 0.22$ & $35.57 \pm 0.36$ & $3.96 \pm 0.35$ & $1.09 \pm 0.20$ \\
\hline DLA+Methotrexate $3.4 \mathrm{mg} / \mathrm{kg}$ & $82.44 \pm 0.27$ & $55.42 \pm 0.29$ & $33.34 \pm 0.65$ & $3.48 \pm 0.27$ & $1.14 \pm 0.48$ \\
\hline
\end{tabular}

Data are expressed as the mean \pm SD of six animals. Values are significant at $p<0.05$. When compared with DLA control group. DLA: Dalton's lymphoma ascites,

HEEAM: Hydroethanolic extract of Annona muricata, SD: Standard deviation, SGPT: Alanine transaminase, SGOT: Aspartate transaminase 


\section{AUTHORS CONTRIBUTION}

The authors have contributed equally to this work.

\section{CONFLICT OF INTERESTS}

Declared none.

\section{REFERENCES}

1. Umesh TG. In vitro antioxidant potential, free radical scavenging and cytotoxic activity of Simarouba gluaca leaves. Int J Pharm Pharm Sci 2014;7:411-6

2. Krishnaveni M, Mirunalini S. Amla-The role of ayurveda therapeutic herb in cancer. Asian J Pharm Clin Res 2011;4:13-7.

3. Kliensmith LJ. Principles of Cancer Biology. $4^{\text {th }}$ ed. San Francisco, CA: Pearson Benjamin Cummings in San Fransisco; 2007. p. 312.

4. Mohan RN, Rajashekhar RN, Kaiser J. Spicy anti-cancer spices: A review. Int J Pharm Pharm Sci 2015;7:1-6.

5. HaldarPK,BhattacharyaS,KarB,BalaA,MazumderUK.Chemoprventive role of Indigofera as palathoides in 20-methylcholanthrene induced carcinogenesis in mouse. Toxicol Enviro Chem 2010;92:1749-63.

6. Armour FE, Blood FR, Belden DA. The Manual for Laboratory Work in Mammalian Physiology. $3^{\text {rd }}$ ed. Chicago: The University of Chicago; 1965 .
7. Morton DB, Griffiths PH. Guidelines on the recognition of pain, distress and discomfort in experimental animals and an hypothesis for assessment. Vet Rec 1985;116:431-6.

8. Sundaresan B, Subbiah M. Antitumor activity of Chondrococcus hornemanni and Spyridia fusiformis on Dalton's lymphoma ascites in mice. Bangladesh J Pharmacol 2012;7:173-7.

9. Jeena K, Liju VB, Kuttan R. Antitumor and cytotoxic activity of ginger essential oil (Zingiber officinale roscoe). Int J Pharm Pharm Sci 2015;7:341-4.

10. Adhvaryu MR, Reddy N, Parabia MH. Effects of four Indian medicinal herbs on Isoniazid, Rifampicin and Pyrazinamide induced hepatic injury and immunosuppresion in guinea. World $\mathrm{J}$ Gastroenterol 2007;13:3199-205.

11. Santoshkumar HD, Shrishailappa B, Ashok G. Antitumor activity of Hypericum Hookerianum against DLA induced tumor in mice and its possible mechanism of action. Phytother Res 2008;22:23-9.

12. Jackson T, Chougule MB, Ichite N, Patlolla RR, Singh M. Antitumour activity of noscapine in human non-small cell lung cancer xenograft model. Cancer J Chemother Pharmacol 2008;63:117-26.

13. Sakthivel KM, Guruvayoorappan C. Acacia ferruginea inhibits tumor progression by regulating inflammatory mediators-(TNF-a, iNOS, COX-2, IL-1AY, IL-6, IFN-I, IL-2, GM-CSF) and pro-angiogenic growth factor-VEGF. Asian Pac J Cancer Prev 2013;14:3909-19.

14. DeWys WD. Pathophysiology of cancer cachexia: Current understanding and areas for future research. Cancer Res 1982;42:721s-726s. 